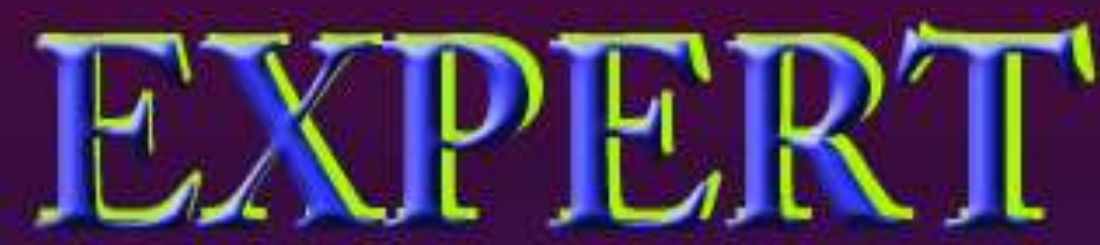

Jurnal Sistem Informasi

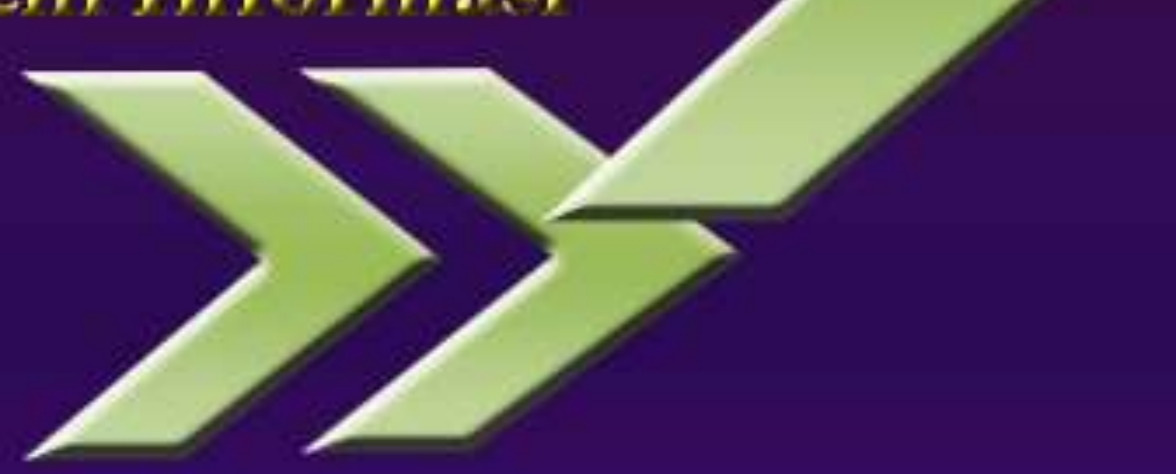

PENGGUNAAN METODE ANALISIS HISTORIS UNTUK MENENTUKAN ANGGARAN PRODUKSI.

Dedi Darwis, Tika Yusiana

PROTOTYPE SISTEM PENUNJANG KEPUTUSAN PENENTUAN KELAYAKAN GUDANG PENERIMAAN PUPUK PUSRI DENGAN METODE SIMPLE ADDITIVE WEIGTHING (SAW).

Sushanty Saleh, Toni Fedrik

ANALISIS SISTEM INFORMASI PENGAWAS KEAMANAN DAN KESEHATAN MAKAN PADA DINAS KESEHATAN KOTA BANDAR LAMPUNG.

Deppi Linda

RANCANG BANGUN APLIKASI VISUALISASI KAMUS BAHASA LAMPUNG BERBASIS ANDROID.

Indera

APLIKASI KOMITE SEKOLAH BERBASIS SMS NOTIFIKASI UNTUK ADMINISTRASI PEMBAYARAN KOMITE.

Fenty Ariani

PEMETAAN SEBARAN MENARA TELEKOMUNIKASI SELULER BERSAMA BERBASIS GIS (GEOGRAPHIC INFORMATION SYSTEM) DI WILAYAH KOTA BANDARLAMPUNG.

TaqwanThamrin, Wiwin Susanty

ISSN : 2088-5555 Write Tn Be Experte 


\section{Expert}

Jurnal Manajemen Sistem Informasi Dan Teknologi

Volume 06, Nomor 02, Desember 2016

\begin{tabular}{|l|c|}
\hline Judul & Hal \\
\hline $\begin{array}{l}\text { PENGGUNAAN METODE ANALISIS HISTORIS UNTUK } \\
\text { MENENTUKAN ANGGARAN PRODUKSI. }\end{array}$ & $42-51$ \\
\hline $\begin{array}{l}\text { PROTOTYPE SISTEM PENUNJANG KEPUTUSAN } \\
\text { PENENTUAN KELAYAKAN GUDANG PENERIMAAN } \\
\text { PUPUK PUSRI DENGAN METODE SIMPLE ADDITIVE } \\
\text { WEIGTHING }(\text { SAW). }\end{array}$ & $52-59$ \\
\hline $\begin{array}{l}\text { ANALISIS SISTEM INFORMASI PENGAWAS } \\
\text { KEAMANAN DAN KESEHATAN MAKAN }\end{array}$ & $60-68$ \\
PADA DINAS KESEHATAN KOTA BANDAR LAMPUNG. & \\
\hline $\begin{array}{l}\text { RANCANG BANGUN APLIKASI VISUALISASI KAMUS } \\
\text { BAHASA LAMPUNG BERBASIS ANDROID. }\end{array}$ & $69-75$ \\
\hline $\begin{array}{l}\text { APLIKASI KOMITE SEKOLAH BERBASIS SMS } \\
\text { NOTIFIKASI UNTUK ADMINISTRASI PEMBAYARAN } \\
\text { KOMITE. }\end{array}$ & $76-84$ \\
\hline $\begin{array}{l}\text { PEMETAAN SEBARAN MENARA TELEKOMUNIKASI } \\
\text { SELULER BERSAMA BERBASIS GIS (GEOGRAPHIC } \\
\text { INFORMATION SYSTEM) DI WILAYAH KOTA BANDAR } \\
\text { LAMPUNG. }\end{array}$ & $85-92$ \\
\hline
\end{tabular}

Fakultas Ilmu Komputer

Universitas Bandar Lampung

\begin{tabular}{|c|l|l|c|c|}
\hline JMSIT & Volume 06 & Nomor 02 & $\begin{array}{c}\text { Lampung } \\
\text { Desember 2016 }\end{array}$ & $\begin{array}{c}\text { ISSN } \\
2088-5555\end{array}$ \\
\hline
\end{tabular}




\section{TIM PENYUNTING}

Ketua Tim Redaksi:

Taqwan Thamrin,ST,M.Sc

Penyunting Ahli

Mustofa Usman, Ph.D

Dr.Iing Lukman,M.Sc.

Usman Rizal, ST.,MMSI

\section{Penyunting:}

Fenty Ariani,S.Kom,M.Kom

Wiwin Susanty,S.Kom,M.Kom

Ayu Kartika Puspa,S.Kom,M.TI

Erlangga,S.Kom,M.Kom

Pelaksana Teknis:

Prima Khoirul Aini, S.Kom

Alamat Penerbit/Redaksi:

Pusat Studi Teknologi Informasi

Fakultas Ilmu Komputer

Universitas Bandar Lampung

Gedung Business Center Lt. 2

Jl,Zainal Abidin Pagar Alam No.26

Bandar Lampung

Telp.0721 - 774626

Email: Journal.expert@ubl.ac.id 


\title{
PEMETAAN SEBARAN MENARA TELEKOMUNIKASI SELULER BERSAMA BERBASIS GIS (GEOGRAPHIC INFORMATION SYSTEM) DI WILAYAH KOTA BANDAR LAMPUNG
}

\author{
Taqwan Thamrin" ${ }^{\# 1}$, Wiwin Susanty ${ }^{* 2}$ \\ \#1*2 Program Studi Sistem Informasi \\ Fakultas Ilmu Komputer Universitas Bandar Lampung \\ Jl. ZA. Pagar ALam no. 26, Labuhan Ratu Bandar Lampung \\ ${ }^{1}$ tagwanthamrinaubl.ac.id \\ ${ }^{2}$ wiwinsusantu@ubl.ac.id
}

\begin{abstract}
Abstrak
Industri telekomunikasi nasional telah mengalami perubahan yang sedemikian pesat, sejak diberlakukannya Undang Undang (UU) Nomor 36 tahun 1999 tentang telekomunikasi. Perubahan lingkungan globaldan perkembangan teknologi telekomunikasi yang berlangsung sangat cepat telah mendorong terjadinya perubahan mendasar, melahirkan lingkungan telekomunikasi yang baru, dan perubahan cara pandang dalam penyelenggaraan telekomunikasi. Hal tersebut, mendorong lahirnya beragam peluang-peluang bisnis di sektor telekomunikasi, khususnya bisnis pendirian menara telekomunikasi. Keberadaan perusahaan yang bergerak dalam bidang pendirian menara ini menjadi sangat penting dan strategis setelah tahun 2008, diberlakukan Peraturan Menteri Komunikasi dan Informatika Nomor 2 tahun 2008 tentang Pembangunan dan Penggunaan Menara bersama Telekomunikasi. Kebijakan ini mengimbas pada perubahan struktur bisnis telekomunikasi yang semakin bebas, kompetitif, dan agresif. Bahwa dalam rangka efektifitas dan efisiensi penggunaan ruang, maka menara harus digunakan secara bersama dan tetap memperhatikan kesinambungan pertumbuhan industri telekomunikasi, kesehatan masyarakat, dan estetika lingkungan. Dengan demikian hal yang harus dilakukan adalah merancang suatu master plan pemetaan sebaran menara telekomunikasi seluler berbasis Sistem Informasi Geografis (SIG) berdasarkan estetika dan kesesuaian dengan rencana tata ruang wilayah kota Bandar Lampung yang kemudian dianalisa untuk zona penempatan menara telekomunikasi seluler bersama baru, berdasarkan kesesuaian terhadap tata ruang kota Bandar Lampung. Jenis penelitian ini merupakan jenis penelitian terapan (applied), penelitian terapan ini merupakan suatu jembatan dari penelitian basic/murni diantara penelitian eksperimental. Teknik pengumpulan data yang dilakukan ada 3 metode yaitu Teknik Wawancara, Dokumentasi dan Observasi.
\end{abstract}

Kata kunci $\quad$ : Sistem Informasi Geografis, Menara telekomunikasi seluler

\section{Pendahuluan}

Teknologi dan industri telekomunikasi saat ini sudah mengalami perkembangan yang sangat pesat, terutama untuk sistem komunikasi nirkabel (wireless) dan atau bergerak (mobile). Hal ini mengakibatkan peningkatan kebutuhan fasilitas-fasilitas yang mendukung terbangunnya suatu jaringan nirkabel, seperti menara telekomunikasi yang menyediakan jaringan untuk berkomunikasi bagi penggunanya.

Pertumbuhan menara telekomunikasi yang menjadi infrastruktur utama dalam penyelenggaraan telekomunikasi sangat dibutuhkan untuk pelayanan dan peningkatan kualitas jaringan telekomunikasi. Untuk membangun menara telekomunikasi ini memerlukan ketersediaan lahan, bangunan dan ruang udara. Bahwa dalam rangka efektifitas dan efisiensi penggunaan ruang, maka menara harus digunakan secara bersama dan tetap memperhatikan kesinambungan pertumbuhan industri telekomunikasi, kesehatan masyarakat, dan estetika lingkungan.

Dengan demikian hal yang harus dilakukan adalah merancang suatu master plan pemetaan menara telekomunikasi seluler berdasarkan estetika dan kesesuaian dengan rencana tata ruang wilayah kota Bandar Lampung yang kemudian dianalisa untuk zona penempatan menara telekomunikasi seluler bersama baru, berdasarkan kesesuaian terhadap tata ruang kota Bandar Lampung.

Berdasarkan latar belakang tersebut, maka permasalahan penelitian dibagi menjadi 3 (tiga) yaitu dengan melakukan identifikasi masalah, menentukan ruang lingkup, serta menentukan rumusan masalah.

\subsection{Identifikasi Masalah}

Identifikasi permasalahan dari penelitian ini, yaitu:

a. Sulitnya Menentukan berapa banyak jumlah menara Telekomunikasi Seluler di wilayah kota bandar lampung.

b. Sulitnya mengidentifikasi dimana letak lokasi yang tidak terjangkau oleh sinyal tower telekomunikasi operator seluler.

c. Belum adanya master plan penataan menara telekomunikasi seluler dan penggunaan menara bersama berdasarkan estetika dan kesesuaian dengan rencana tata ruang wilayah (rtrw) kota Bandar Lampung.

\subsection{Ruang Lingkup}

Ruang lingkup permasalahan ini hanya dibatasi hanya pada ruang lingkup pembuatan master plan menara telekomunikasi bersama dan identifikasi 
terhadap kondisi eksisting dari tower yang sudah ada di wilayah kota bandar lampung.

\subsection{Tujuan Penelitian}

Tujuan penelitian ini adalah:

1. Penerapan GIS (Geographic Information System) untuk membuat Master Plan menara Telekomunikasi Bersama yang akan menjadi pedoman dalam melaksanakan penataan dan pembangunan menara serta mengurangi dampak negatif pembangunan tower terhadap lingkungan sekitar bagi pemerintah daerah.

2. Menghasilkan aplikasi baru dalam bidang telekomunikasi karena menghasilkan database sebaran menara telekomunikasi bersama diwilayah kota bandar lampung.

\section{Landasan Teori}

\subsection{Tinjauan Pustaka}

Dalam Tinjauan Pustaka ini akan diuraikan hasilhasil dari penelitian lainnya yang pernah dilakukan dan mempunyai kaitan dengan topik penelitian ini adalah

a. Perancangan Sistem Informasi Geografis Tempat Pariwisata Kabupaten Cilacap Berbasis Web [Sri Sutanti, 2012]. Objek wisata dan sarana pendukung pariwisata yang tersebar di Kabupaten Cilacap masih belum banyak yang mengetahui keberadaannya, sehingga membuat sebagian orang mengalami kesulitan dalam memperoleh informasi tentang lokasi pariwisata di kabupaten Cilacap tersebut. Untuk itu sangat perlu dibuat suatu sistem informasi sebagai pemetaan,pengelolaan data informasi lokasi pariwisata dan sarana pendukung lainnya seperti, pendukung website resmi dibuat sebuah fitur pemetaan yang menyajikan informasi lokasi berbasis digital dan imaging yang dapat diakses dengan mudah. Website Pariwisata di kabupaten Cilacap merupakan sarana penting yang memberikan informasi secara online. Pada website tersebut tersedia peta statis yang memberikan informasi objek wisata dalam bentuk gambar, namun dalam peta statis ini belum dapat memberikan informasi objek wisata secara detail sehingga hingga dalam hal akses belum informative. Untuk itu sangat perlu dibuat dalam pendukung website resmi dibuat suatu fitur tambahan dalam pemetaan yang menyajikan informasi berbentuk digital dan imaging agar dapat di akses dengan mudah. Dalam mendukung perancangan website sistem informasi geografis objek pariwisata dibupaten cilacap ini dibutuhkan suatu metode dan pendekatan dalam penyelsaiannya yaitu dengan menganalisis kelemahan sistem yang berjalan saat ini, menganalisis kebutuhan sistem saat ini dan menganalisi kelayakan sistem saat ini. Webite sistem informasi geografis lokasi kabupaten Cilacap sangat dibutuhkan dikarenakan kabupaten cilacap merupakan salah satu sektor utama dalam hal pendapatan (PAD) Cilacap. Maka untuk itu dibuatlah perancangan sistem informasi geografis tempat lokasi pariwisata kabupaten Cilacap berbasis web.

b. Aspek Regulasi

Pada Peraturan Menteri Komunikasi dan Informatika No. 2/PER/M.KOMINFO/3/2008 tentang Pedoman Pembangunan dan Penggunaan Bersama Menara Telekomunikasi memberi kewenangan pada Pemerintah Daerah untuk turut serta mengatur dan bertanggung jawab dalam menyusun rencana pembangunan dan penggunaan menara bersama. Peraturan Bersama Menteri Dalam Negeri, Menteri Pekerjaan Umum, Menteri Kominfo dan Kepala BKPM tentang Pedoman Pembangunan dan Penggunaan Bersama Menara Telekomunikasi No. 18 Tahun 2009, No. 07/PRT/M/2009, No. 19/PER/M.KOMINFO/3/2009 dan No. 3/P/2009, merupakan peraturan yang lebih terperinci mengenai menara bersama. Beberapa aturan tambahan dalam peraturan bersama ini antara lain memberikan waktu tenggat selama dua tahun bagi menara yang telah berdiri untuk beralih ke konsep menara bersama, tidak diperbolehkannya monopoli menara bersama di satu wilayah, pemberian kesempatan yang sama untuk semua operator telekomunikasi pada satu menara bersama, dan memprioritaskan menara telekomunikasi eksisting sebagai menara bersama apabila berada di lokasi yang telah sesuai dengan rencana tata ruang wilayah.

\subsection{Tinjauan Studi}

\subsubsection{Sistem Informasi Geografis}

Sistem informasi geografi (SIG) adalah sistem berbasis komputer yang digunakan untuk menyimpan, memanipulasi dan menganalisis informasi geografi. [Zeng, et al. 2008] Yang semula informasi permukaan bumi disajikan dalam bentuk peta yang dibuat secara manual, maka dengan hadirnya SIG informasiinformasi itu diolah oleh komputer, dan hasilnya berupa peta digital. SIG mampu menyajikan keaslian dan kelengkapan sebuah informasi dibandingkan cara-cara yang digunakan sebelumnya. Sistem informasi geografi menyimpan data sesuai dengan data aslinya. Walaupun demikian, agar data yang disimpan itu akurat, maka data yang dimasukkan haruslah data yang akurat. SIG akan memberikan informasi yang kurang akurat bila data yang dimasukkan merupakan data yang meragukan.

Selain berperan sebagai alat pengolah data keruangan, sistem informasi geografi juga mampu menyajikan informasi mengenai sumber daya yang dimiliki oleh suatu ruang atau wilayah tertentu. Dengan demikian, sistem informasi geografi tidak hanya befungsi sebagai "alat pembuat peta", tetapi lebih jauh dari itu. Sistem informasi geografi mampu menghasilkan suatu sistem informasi yang aplikatif, 
yang dapat digunakan oleh perencana atau oleh pengambil keputusan untuk kepentingan pengolahan sumber daya yang ada di suatu wilayah. Geografi [Zhenghua, et al, 2011].

\subsubsection{Konsep SIG}

Sistem Informasi Geografis (SIG) adalah teknologi baru yang dapat digunakan sebagai alat untuk menganalisis dan mentransfer data kebumian. Menurut Zeng, et al., (2008) sistem informasi geografis adalah suatu alat yang dapat digunakan untuk mengumpulkan, menyimpan, mendapatkan kembali, mentransformasi, dan menayangkan kembali data keruangan dari dunia nyata untuk tujuan tertentu. Dengan kata lain, SIG adalah suatu sistem berbasis komputer yang dapat mengolah dan menginformasikan unsur alam dan unsur buatan yang bergeoreferensi. Unsur bergeoreferensi artinya unsur tersebut mempunyai acuan posisi tertentu dimuka bumi. Gambar di bawah menjelaskan visualisasi SIG dan gambar 2 overlay lapisan badan air, drainase, jaringan jalan dan daratan.

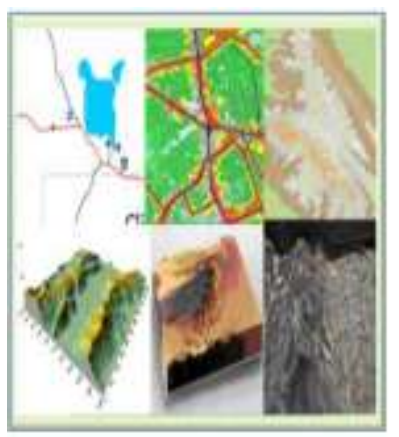

Gambar 1. Peta Kontur

SIG mempunyai kemampuan untuk mengolah data grafis, non-grafis secara terpadu. Agar supaya konsep SIG dapat terwujud, maka diperlukan 5 komponen, yaitu sumber daya manusia, data, perangkat lunak, perangkat keras dan manajemen. Kelima komponen tersebut saling terkait satu dengan lainnya [Zhenghua et al, 2011]. Penerapan sistem informasi geografis sudah berkembang untuk berbagai bidang, antara lain : (1). Pemetaan kadaster, (2). Pemetaan jalan raya, (3). Perencanaan kota dan wilayah, (4). Pemilihan rute jalan raya, dan jalur transmisi, (5). Bidang teknik sipil, (6). Bidang kesehatan, (7). Proses kartografi. Keunggulan SIG terletak pada kemampuannya memadukan data untuk memperoleh informasi baru berdasarkan database yang sudah ada, dan analisis keruangan (geospatial) serta integrasi. data vektor, raster, dan data atribut.

\subsubsection{Komponen-komponen SIG}

Secara umum Sistem Informasi Geografis (SIG) memiliki 5 (lima) komponen utama yang satu sama lain sangat mempengaruhi keberhasilan penerapan sistem tersebut dalam segala keperluan, termasuk untuk keperluan pengembangan pada Sistem database tower telekomunikasi. Pada Error! Reference source not found. ditunjukkan komponen-komponen tersebut dan hubungannya satu dengan yang lain. Terlihat dengan jelas bahwa kelima komponen tersebut adalah Data, Methods (metode), People (sumber daya manusia), Hardware (perangkat keras system komputer), dan Software (perangkat lunak). Sistem informasi meliputi software, hardware dan data. Software merupakan perangkat lunak dalam komputer untuk mengolah data yang berasal dari perangkat keras (hardware), Peta merupakan representasi grafik dari elemen geografi yang terdistribusi menurut keruangan (geospatial), dinamakan juga feature peta (map feature). Feature peta ini disajikan dengan sekumpulan elemen grafik seperti titik, garis dan area. Peta menyampaikan :

1 Informasi tentang lokasi unsur / obyek alam buatan manusia, karakteristik unsur dan hubungan keruangan dengan unsur yang lainnya.

2 Data peta digital merupakan feature peta yang disimpan dalam besaran-besaran numeris dan angka-angka koordinat. Jadi data yang disajikan tidak lagi berupa lembaran-lembaran peta tetapi sudah dalam bentuk digital. Data geografis sebagai data keruangan (spatial data) dapat disajikan baik sebagai titik (point), garis (line), ataupun bidang (area). Dengan dukungan perangkat keras dan perangkat lunak komputer, maka data tersebut dapat diolah dan dimanipulasi untuk berbagai kebutuhan dalam SIG. Hal ini tentunya dapat dilakukan karena data dalam bentuk digital bersifat fleksibel dan mudah diperbaharui. Berbeda halnya dengan peta-peta konvensional yang terbatas dalam menyajikan informasi, maka peta digital dapat memuat berbagai macam informasi yang dikumpulkan dalam suatu database. Disamping data grafis (peta), maka SIG memerlukan data non-grafis (atribut/non spasial). Data atribut yang dibutuhkan tergantung dari kebutuhan dan tujuan pemakaian SIG itu sendiri. Data atribut harus disimpan dalam bentuk digital, sehingga akan mudah digabungkan dengan data grafisnya.

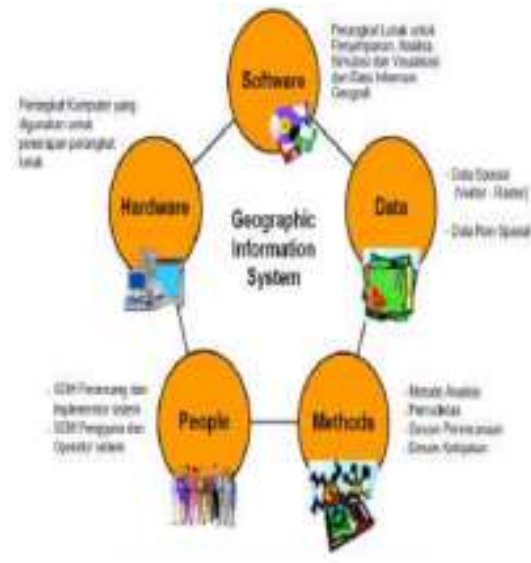

Gambar 2. Komponen SIG [Syafruddin Rauf, 2012]

\subsubsection{Tahapan dalam SIG}


Secara khusus, perangkat lunak GIS/SIG (Geographic Information Systems), terdiri dari tiga tahapan yaitu tahapan Input, Proses dan Analisis, ,Output dan Visualisasi. Gambar 3 berikut menjelaskan diagram kerja perangkat lunak tersebut. Secara khusus, perangkat lunak GIS (Geographic Information Systems), terdiri dari tiga tahapan yaitu tahapan Input, Proses dan Analisis, ,Output dan Visualisasi. Gambar 3 menjelaskan diagram perangkat lunak tersebut.

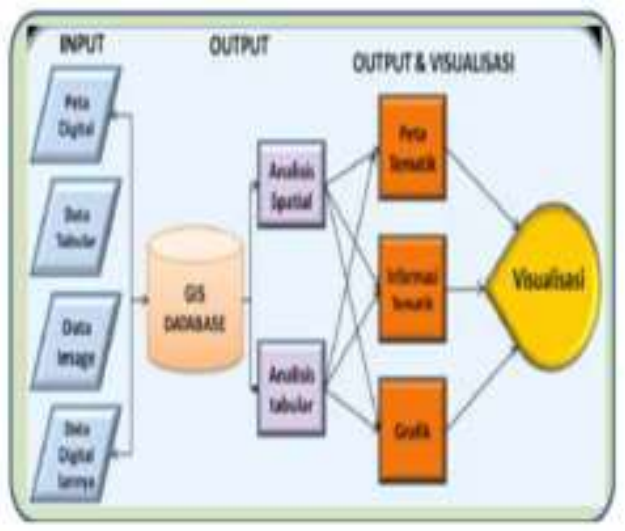

Gambar 3. Diagram Perangkat Lunak SIG

1. Input, Aplikasi GIS menerima data-data masukan dari pengguna maupun dari pengembang sistem. Adapun data-data yang dapat dijadikan data masukan bagi sistem tersebut adalah sebagai berikut:

> Peta Digital, Data utama yang membedakan sistem informasi geografik dengan sistem informasi lainnya adalah kemampuannya dalam menampilkan dan menangani basis data spasial atau data bergeoreferensi. Dalam hal inilah keberadaan peta digital menjadi sangat esensial bagi system ini.

$>$ Data Tabular, Yang dimaksud dengan data tabular adalah data-data yang berupa teks, angka, ataupun biner yang disimpan dalam bentuk tabel-tabel. Terdapat 2 (dua) jenis data tabular yang dimaksud, yaitu data tabular yang terikat dengan objek dalam peta dan yang tidak terikat.

$>$ Data Image, Database SIG dapat menerima data masukan berupa foto digital, gambar, dan objek grafis digital lainnya. Data-data tersebut dapat ditampilkan sebagai data pelengkap, misalnya: foto Lokasi Bangunan, Infrastruktur Tower, tapal batas, obyek vital, dan berbagai macam hal lainnya.

$>$ Data Digital Lainnya, Secara umum, hampir semua jenis data dalam bentuk digital yang ingin dicantumkan dan ditampilkan dapat diterima dan disimpan dengan baik oleh basis data GIS dan dapat pula ditampilkan sesuai dengan kebutuhan. Selain data peta digital, data image, dan data tabular, data-data berbentuk digital lainnya juga dapat dengan mudah diikutkan dalam sistem ini: musik, animasi, atau film misalnya.

2. Analisis, Data yang tersimpan dalam sistem basis data yang bersangkutan kemudian dijadikan bahan untuk melakukan analisis sehingga dapat ditarik sebuah informasi darinya sesuai dengan kebutuhan pengguna dan pemilik sistem. Adapun analisis-analisis yang dapat dilakukan dalam sistem ini adalah sebagai berikut: Analisis Spasial, Analisis Tabular, Analisis numeris, Analisis Statistik, Analisis Tekstual.

3. Output Keluaran dari proses analisis-analisis yang telah disebutkan sebelumnya adalah berupa informasi-informasi yang diinginkan oleh pengguna. Informasi tersebut disajikan dalam berbagai bentuk yaitu peta tematik, tabel, dan grafik. Salah satu keunggulan GIS adalah kemampuannya untuk menghasilkan sebuah peta tematik sebagai hasil analisis nya. Peta tematik yang dihasilkan selain dapat ditampilkan pada monitor komputer pada saat analisis selesai dilakukan, ia dapat juga disimpan dan dipanggil lagi saat diperlukan, dan dicetak di atas kertas setelah dilakukan penyesuaian terhadapnya.

\section{Metode Penelitian}

\subsection{Analisa Kebutuhan}

Untuk penerapan SIG untuk pemetaan Sebaran menara Telekomunikasi Seluler Bersama di wilayah kota Bandar Lampung dibutuhkan data-data dalam pengujiannya sehingga dapat menghasilkan hasil yang akurat dan sesuai.

\subsection{Metode Pengumpulan Data}

Pada Penelitian ini dilakukan beberapa teknik/metode pungumpulan data yaitu:

a. Observasi

Observasi merupakan teknik atau pendekatan untuk mendapatkan data primer dengan cara mengamati langsung objek datanya [Sugiono, 2012]. Data primer adalah data yang diperoleh secara langsung melalui pengamatan langsung di lapangan (survei), untuk mendapatkan kondisi yang nyata.

b. Dokumentasi/data arsip

Untuk memperoleh Informasi peneliti juga mencari informasi dari dokumen-dokumen yang ada untuk mendapatkan data primer dan sekunder. Dan mengumpulkan data yang sudah diolah didalam database sebagai data serta informasi didalam penelitian ini.

\subsection{Perancangan Sistem}

Dalam penelitian ini akan dilakukan beberapa tahapan, dimana tahapan ini dapat dilihat pada Gambar 4 di bawah ini, 


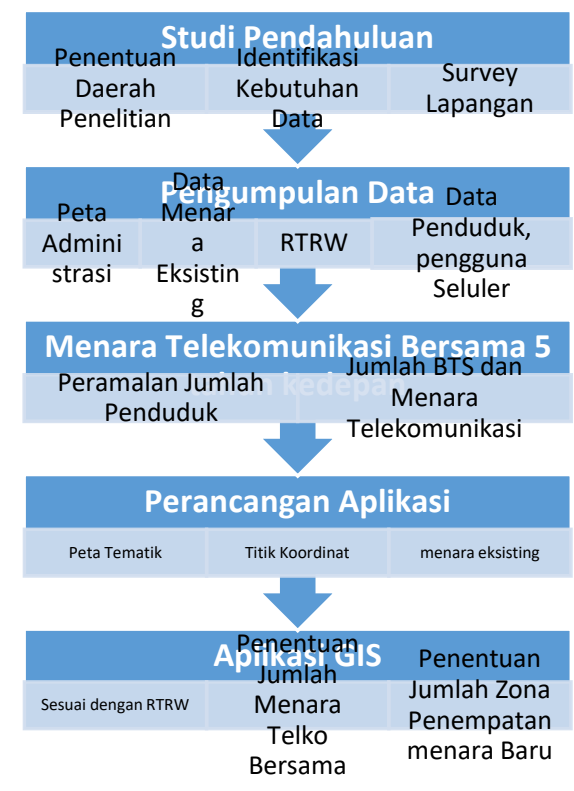

Gambar 4. Desain Penelitian

\section{Hasil dan Pembahasan}

\subsection{Hasil}

\subsubsection{Antar Muka Pengguna}

GUI (Graphical User Interface) merupakan antar muka pengguna suatu program berbasis grafis, yakni perintah-perintah tidak diketik melalui keyboard, berikut adalah beberapa tampilan antar pengguna untuk berinteraksi dengan sistem pada Perancangan SIG untuk identifikasi letak tower Telekomunikasi operator seluler di Bandar lampung.

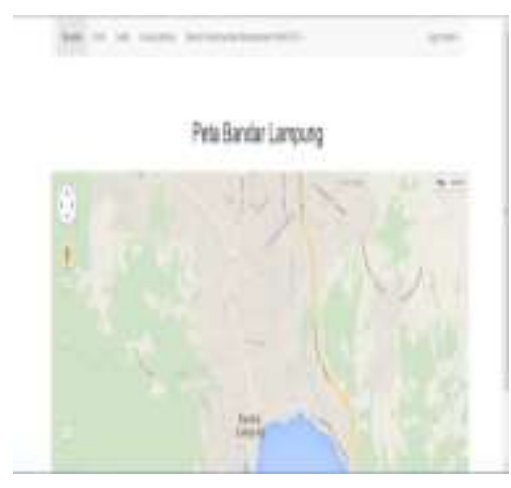

Gambar 5. Menu Halaman awal

Pada halaman awal Perancangan SIG untuk Identifikasi Tower Letak Telekomunikasi Operator Seluler di Bandar Lampung ini terdapat beberapa menu diantaranya:

\section{a. Beranda}

Pada Menu beranda disini hanya menampilkan halam utama dari Perancangan SIG untuk Identifikasi Letak Tower Telekomunikasi Operator Seluler di Bandar Lampung.

\section{b. Profil}

Pada menu profil ini menampilkan tujuan dari Perancangan SIG untuk Identifikasi Letak Tower
Telekomunikasi Operator Seluler di Bandar Lampung ini.

c. Grafik

Pada menu grafik ini menampilkan jumlah grafik dari jumlah tower telekomunikasi operator selluler yang ada di Bandar Lampung.

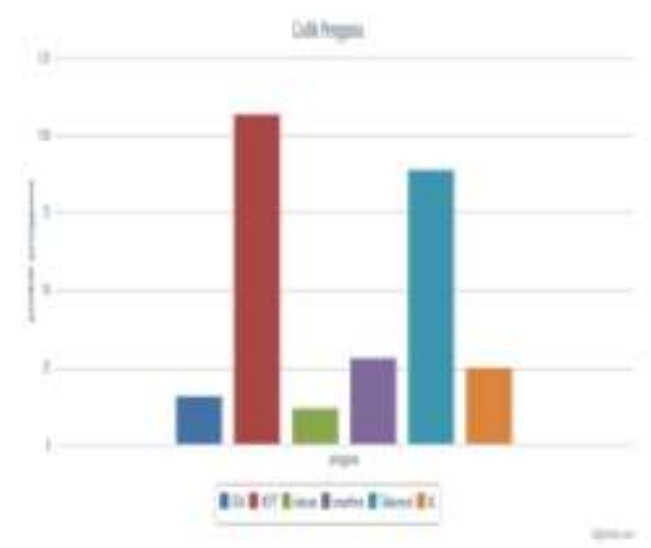

Gambar 6. Menu Grafik

\section{d. Semua Menara}

Pada menu semua menara menampilkan keseluruhan letak tower telekomunikasi operator seluler yang ada di Bandar Lampung

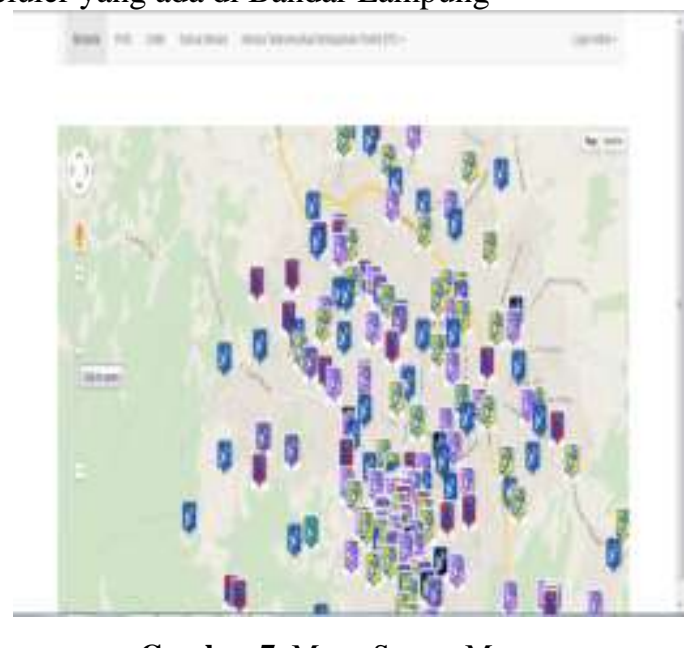

Gambar 7. Menu Semua Menara

\section{e. Menara Telekomunikasi Berdasarkan BTS}

Pada menu menara telekomunikasi berasarkan BTS ini meampilkan menu yang akan di pilih oleh pengguna SIG diantaranya Protelindo, XL Asiata, TBG, Telkomsel, HCPT, RADIO dan SMARTFREN. 


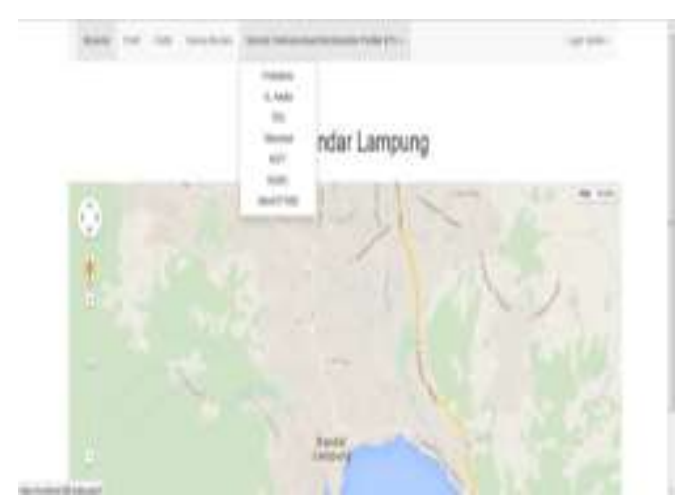

Gambar 8. Menu Menara Telekomunikasi Berdasarkan BTS

\section{f. Menu Login Admin}

Pada halaman login admin ini, yang hanya dapat login hanyalah admin yang bertugas untuk menginput data dan melihat data tower telekomunikasi operator seluler. Sedangkan user hanya dapat melihat letak tower telekomunikasi operator seluler yang telah di input oleh admin.

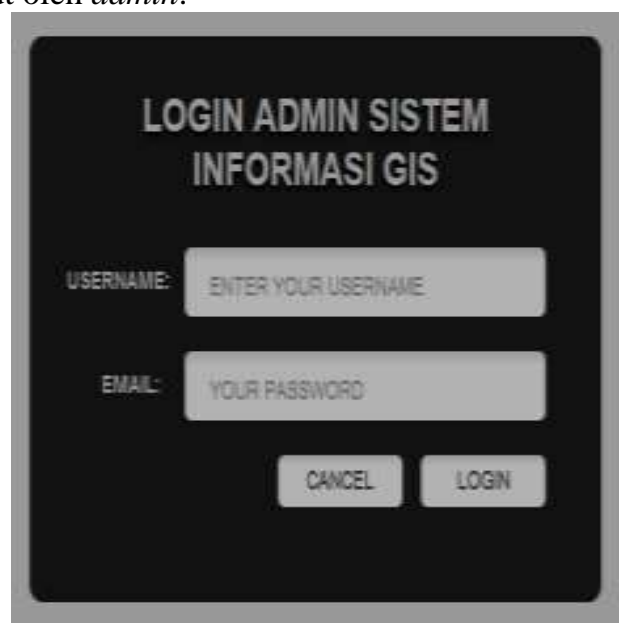

Gambar 9. Menu Login Admin

Setelah admin melakukan login dan sukses maka akan terdapat tampilan seperti pada Gambar 10 Halaman awal setelah admin sukses melakukan login admin .

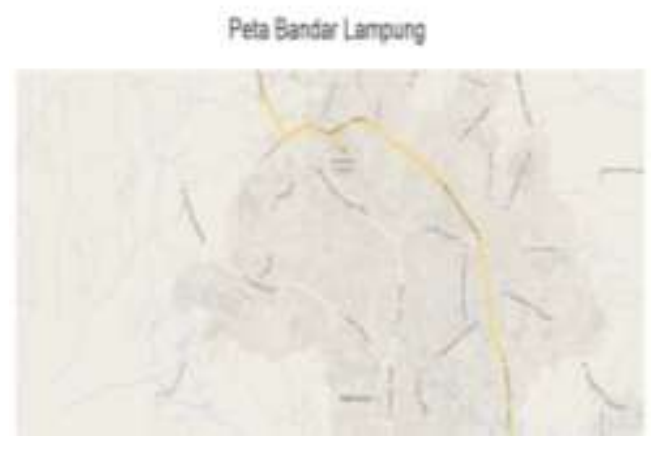

Gambar 10. Halaman Awal Setelah Login Admin
Pada Halaman awal setelah admin sukses melakukan login admin ini admin terdapat beberapa menu pilihan yaitu diantaranya :

1) Beranda

Pada menu beranda disini hanya menampilan peta Bandar Lampung.

2) Profil

Pada menu profil disini admin dapat mengubah (edit), menghapus (delete) serta menambahkan (input) keterangan tentang Perancangan SIG mengenai tower Telekomunikasi Operator Seluler yag ada di Bandar Lampung.

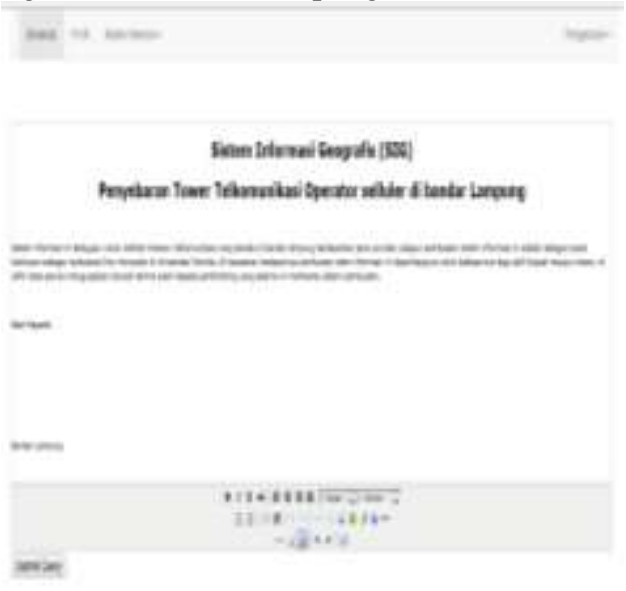

Gambar 11. Menu Profil Setelah Login Admin

\section{3) Master Menara}

Pada menu master menara teradapat data menara (tower) yang telah di input oleh admin. Admin dapat mengubah (edit), menghapus (delete), serta menambahkan (input) data menara (tower) Telekomunikasi Operator Seluler yang ada di Bandar Lampung.

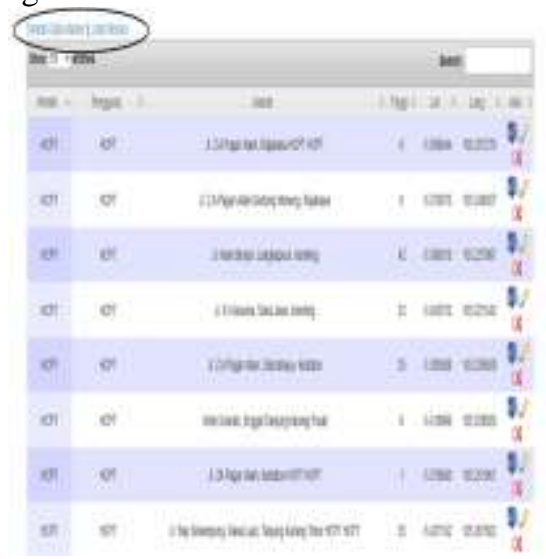

Gambar 12. Menu Master Menara

Pada data master terdapat dua menu pilihan yaitu Tambah Data Master dan Lihat Menara, pada menu pilihan Tambah Data Master akan tampil seperti Gambar 13 Menu Tambah Data Master. 


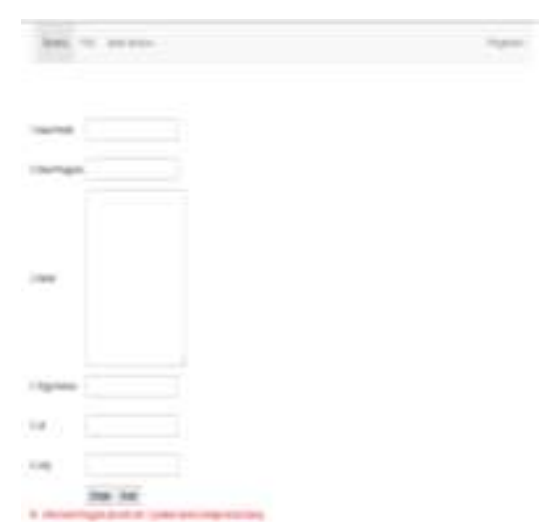

Gambar 13. Menu Tambah Data Master

Pada menu ini admin dapat menambahkan data master yang akan di tampilkan pada web SIG untuk Identifikasi Letak Tower Telekomunikasi Operator Seluler yang ada di Bandar Lampung. Sedangkan pada menu pilihan Lihat Menara akan tampil seperti pada Gambar 14 Menu Lihat Menara Setelah Login Admin.

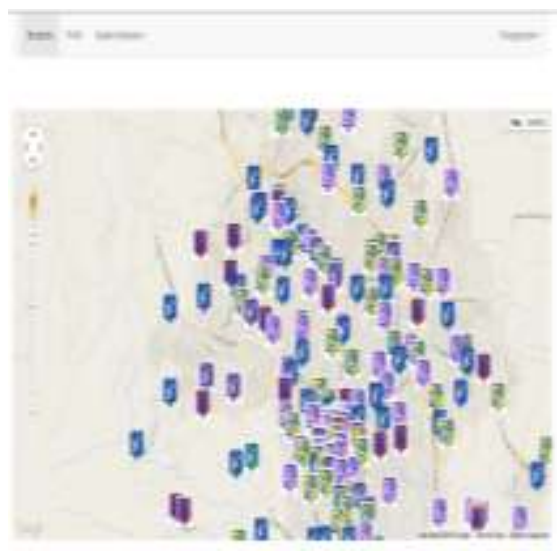

Gambar 14. Menu Lihat Menara

Pada tampilan menu lihat menara ini admin dapat melihat hasil dari data menara yang telah ditambahkan pada SIG untuk Identifikasi Letak Tower Telekomunikasi Operator Seluler.

\section{Kesimpulan dan Saran}

\subsection{Kesimpulan}

Berdasarkan hasil penelitian yang telah dilakukan mulai dari tahap perancangan hingga pengujian terhadap Perancangan aplikasi pemetaan sebaran menara telekomunikasi seluler bersama berbasis SIG di wilayah kota Bandarlampung, maka kesimpulan yang dapat diambil dari penelitian ini adalah sebagai berikut :

1. Perancangan SIG ini dirancangan dengan beberapa tahapan yaitu : Menganalisis sistem yang telah dibuat, Pengumpulan Data, Perancangan Database, Desain Program, dan Implementasi.

2. Perancangan SIG ini dapat diterapkan dengan Menerapkan Perancangan SIG kepada Badan Pengawas Pembangunan dan Pengendalian BTS
(Base Transceiver Station) untuk identifikasi letak tower telekomunikasi operator seluler di Bandar Lampung, supaya Badan Pengawas Pembangunan dan Pengendalian BTS (Base Transceiver Station) dapat dengan mudah mengawasi dan mengidentifikasi letak tower telekomunikasi operator seluluer yang ada di Bandar Lampung. Perancangan SIG untuk identifikasi letak tower telekomunikasi operator seluler di Bandar Lampung telah dapat digunakan di karenakan SIG ini telah dapat di gunakan dalam identifikasi letak tower telekomunikasi operator seluler yang ada di Bandar Lampung dan waktu yang dibutuhkan dalam identifikasi maupun input letak tower telekomuniasi operator seluler yang ada di Bandar Lampung relative lebih singkat di bandingkan dengan proses pencarian manual.

\subsection{Saran}

Adapun saran yang di sampaikan dalam penelitian ini yaitu :

1. Perlu adanya menu tambahan dalam menentukan titik lokasi penempatan tower telekomunikasi yang baru agar hasil dari SIG ini dapat dipergunakan lebih maksimal dalam penggunaannya

2. Diharapkan penelitian mengenai SIG ini dapat di jadikan acuan bagi penelitian selanjutnya agar hasil dari penelitian ini dapat di bandingkan dengan pendekatan yang lain.

\section{Acknowledgements}

Ucapan terima kasih pada Kementerian Riset, Teknologi dan Pendidikan Tinggi, Direktorat Jenderal Penguatan Riset dan Pengembangan atas dana dan terlaksananya penelitian ini dalam skema penelitian dosen pemula tahun anggaran 2016.

\section{Daftar pustaka}

[1] Direktur Jenderal Penataan Ruang Kementerian Pekerjaan Umum, "Petunjuk Teknis Kriteria Menara Telekomunikasi”. Surat Edaran Nomor 06/SE/Dr/2011. Jakarta, September. 2011.

[2] Kementerian Komunikasi dan Informasi Republik Indonesia (2008).'Pedoman Pembangunan dan Penggunaan Menara Bersama Telekomunikasi", Kementerian Kominfo, Jakarta. 2008.

[3] Sri Sutanti (2012), "Perancangan Sistem Informasi Geografis Tempat Pariwisata Kabupaten Cilacap Berbasis Web"

[4] Sugiyono (2012)."Metode Penelitian Kuantitatif Kualitatif dan R\&D”, AlfaBeta, Bandung.

[5] Syafruddin Rauf. (2012). "Pemetaan Jaringan Drainase Berbasis Quantum GIS Open Source di Kota Makassar", Jurnal Prosiding Hasil Penelitian Fakultas Teknik Vol.8 Desember 2012. ISBN: 978-978-127255-0-6.

[6] Zeng Liansun, Wang Liang, dan Ding Chinling (2008). "Site Selection for Wireless base station based on Map Partitioning” IEEE.2008. 
[7] Zhenghua Shu, Hong Li, Guodong Liu, dan Qing Xie (2011), "Application of GIS in Telecomunication Information Resources Management System". InternationalConference on Information Management, Innovation Management, and Industrial Engineering. 2011. 
Redaksi :

Pusat Study Teknologi Informasi (PSTI).

Gedung Business Center Lt 2

Jl. Zainal Abidin No. 26 Bandar Lampung

Telp. 0721 - 774626 